\title{
A Comprehensive Study on Gamma Rays and Fast Neutron Sensing Properties of GAGOC and CMO Scintillators for Shielding Radiation Applications
}

\author{
Shams A. M. Issa, ${ }^{1,2}$ M. I. Sayyed, ${ }^{1}$ M. H. M. Zaid, ${ }^{3,4}$ and K. A. Matori ${ }^{3,4}$ \\ ${ }^{1}$ Department of Physics, Faculty of Science, University of Tabuk, Tabuk, Saudi Arabia \\ ${ }^{2}$ Department of Physics, Faculty of Science, Al-Azhar University, Cairo, Egypt \\ ${ }^{3}$ Department of Physics, Faculty of Science, Universiti Putra Malaysia, 43400 Serdang, Selangor, Malaysia \\ ${ }^{4}$ Materials Synthesis and Characterization Laboratory, Institute of Advanced Technology, Universiti Putra Malaysia, 43400 Serdang, \\ Selangor, Malaysia
}

Correspondence should be addressed to K. A. Matori; khamirul@upm.edu.my

Received 3 April 2017; Revised 10 July 2017; Accepted 26 July 2017; Published 26 September 2017

Academic Editor: Tino Hofmann

Copyright (c) 2017 Shams A. M. Issa et al. This is an open access article distributed under the Creative Commons Attribution License, which permits unrestricted use, distribution, and reproduction in any medium, provided the original work is properly cited.

\begin{abstract}
The WinXCom program has been used to calculate the mass attenuation coefficients $\left(\mu_{m}\right)$, effective atomic numbers $\left(Z_{\text {eff }}\right)$, effective electron densities $\left(N_{\mathrm{el}}\right)$, half-value layer $(\mathrm{HVL})$, and mean free path (MFP) in the energy range $1 \mathrm{keV}-100 \mathrm{GeV}$ for $\mathrm{Gd}_{3} \mathrm{Al}_{2} \mathrm{Ga}_{3} \mathrm{O}_{12} \mathrm{Ce}(\mathrm{GAGOC})$ and $\mathrm{CaMoO}_{4}(\mathrm{CMO})$ scintillator materials. The geometrical progression (G-P) method has been used to compute the exposure buildup factors $(\mathrm{EBF})$ and gamma ray energy absorption (EABF) in the photon energy range $0.015-15 \mathrm{MeV}$ and up to a 40 penetration depth ( $\mathrm{mfp}$ ). In addition, the values of the removal cross section for a fast neutron $\left(\sum_{R}\right)$ have been calculated. The computed data observes that GAGOC showed excellent $\gamma$-rays and neutrons sensing a response in the broad energy range. This work could be useful for nuclear radiation sensors, detectors, nuclear medicine applications (medical imaging and mammography), nuclear engineering, and space technology.
\end{abstract}

\section{Introduction}

Due to the great importance of inorganic scintillator materials in the field of ionizing nuclear radiation detection, they are a very suitable to utilize in many applications such as technology of space, the design of nuclear devices, and medicinal diagnostics [1]. To develop the new scintillator materials, the knowledge of mass attenuation coefficient $\left(\mu_{m}\right)$ is very considered for scintillators because the results of $\mu_{m}$ show the probability of interaction. Furthermore, when the gamma ray interacts with the material, the half-value layer (HVL), mean free path (MFP), effective atomic number $\left(Z_{\text {eff }}\right)$, effective electron density $\left(N_{\mathrm{el}}\right)$, exposure buildup factors $(\mathrm{EBF})$, and gamma ray energy absorption (EABF) are the fundamental quantities required to explain the penetration of nuclear radiation in matter. HVL, MFP, $Z_{\mathrm{eff}}, N_{\mathrm{el}}$, $\mathrm{EBF}$, and EABF parameters can be computed utilizing the values of $\mu_{m}$ [2]. Precise $\mu_{m}$ values are wanted to provide fundamental results in many nuclear radiation fields like computerized tomography, radiation shielding, nuclear radiation dosimeter, fluorescence of gamma ray, and safety inspection [3]. Various other researchers reported the properties of gamma radiation shielding for alloys, multielemental materials, soils, solutions, polyvinyl alcohol, and biological materials [4-11].

Hine [12] suggested a number of composite changes with energy called effective atomic number $\left(Z_{\text {eff }}\right)$ to characterize the atomic number of mixed materials with energy. Due to the high light yield, speedy decay time, high density, high $Z_{\text {eff }}$, and good energy resolution of GAGOC scintillator materials, it is a great nominee for many applications like gamma spectroscopy and position emission tomography (PET) [13]; furthermore, GAGOC does not have natural radioactivity [14]. Because there is lack of knowledge of gamma ray and neutron 
interaction with GAGOC and CMO scintillator materials, $\mu_{m}, \mathrm{HVL}, \mathrm{MFP}, Z_{\mathrm{eff}}, N_{\mathrm{el}}$, EBF, and EABF have been investigated in a broad energy range. The values have been computed for $\mu_{m}, \mathrm{HVL}, \mathrm{MFP}, Z_{\mathrm{eff}}$, and $N_{\mathrm{el}}$ in the energy range $1 \mathrm{keV}-100 \mathrm{GeV}$ and for EBF and EABF in the energy range $0.015-15 \mathrm{MeV}$ using the WinXCom program. Also, the macroscopic fast neutron removal cross section $\left(\sum_{R}\right)$ has been calculated.

\section{Theory}

Photoelectric effect, Compton scattering, and pair production mechanisms can explain the interaction of photons with the GAGOC and CMO scintillator materials. If the intensity of the initial beam penetrates the sample which is $I_{0}$, the intensity of the beam will be attenuated and exponentially decreased to $I$ according to the Beer-Lambert law.

$$
\mu_{m}=\frac{\ln \left(I_{0} / I\right)}{\rho d},
$$

where $I_{0}$ is the intensity of bombarding beam, $I$ is the intensity of transmitting beam, $\rho$ is the density of scintillator samples $\left(\mathrm{g} / \mathrm{cm}^{3}\right)$, and $d$ is the thickness of the samples $(\mathrm{cm})$. The total photon interaction cross section $\left(\sigma_{t}\right)$ of the samples has been calculated with the help of the $\mu_{m}$ according to the following equation:

$$
\sigma_{t}=\frac{M \mu_{m}}{N_{\mathrm{A}}},
$$

where $M=\sum_{i} A_{i} n_{i}$ is the molecular weight of the sample, $A_{i}$ is the atomic weight of the $i$ th element, $n_{i}$ is the number of the formula units of a molecule, and $N_{\mathrm{A}}$ is the Avogadro's number. Effective atomic cross section, $\sigma_{a}$, has been calculated using the following equation:

$$
\sigma_{a}=\frac{\sigma_{a}}{\sum_{i} n_{i}} .
$$

Total electronic cross section, $\sigma_{e}$, has been calculated by

$$
\sigma_{e}=\frac{1}{N_{\mathrm{A}}} \sum_{i} \frac{f_{i} A_{i}}{Z_{i}}\left(\mu_{m}\right)_{i},
$$

where $f_{i}$ indicates to the fractional abundance of the element $i$ and $Z_{i}$ the atomic number of the constituent element. The $Z_{\text {eff }}$ is related to $\sigma_{a}$ and $\sigma_{e}$ through the following equation:

$$
Z_{\mathrm{eff}}=\frac{\sigma_{a}}{\sigma_{e}} .
$$

The effective electron densities $\left(N_{\mathrm{el}}\right)$ of GAGOC and $\mathrm{CMO}$ have been calculated from the following:

$$
N_{\mathrm{el}}=\frac{Z_{\mathrm{eff}} N_{\mathrm{A}}}{M} \sum_{i} n_{i} .
$$

Half-value thickness (HVL) is the thickness of any given material where $50 \%$ of the incident energy has been

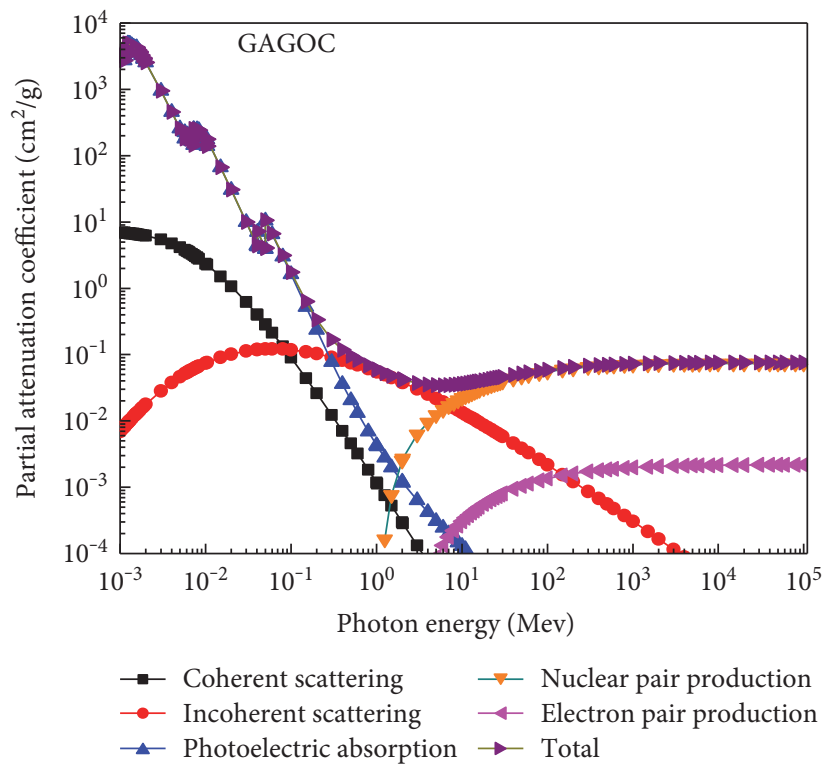

FIgURE 1: Variation of the total and partial mass attenuation coefficient of GAGOC versus incident photon energy.



Figure 2: Variation of total mass attenuation coefficients versus incident photon energy for GAGOC and CMO.

attenuated and has been computed utilizing the linear attenuation coefficient $(\mu)$ through the following equation:

$$
\mathrm{HVL}=\frac{0.639}{\mu} .
$$

One of the other values that are calculated in this study of GAGOC and CMO is the mean free path (MFP) which is described in $[15,16]$. For the detailed knowledge on calculations of the parameters of G-P fitting, exposure buildup factor and energy absorption buildup factor, the element G-P fitting parameters have been taken from the ANSI/ANS 6.4.3 [17]. 
TABLE 1: K-, L-, and M-absorption edges (keV) for elements.

\begin{tabular}{lcccccccccc}
\hline Element & $\mathrm{Z}$ & $\mathrm{K}$ & $\mathrm{L}_{1}$ & $\mathrm{~L}_{2}$ & $\mathrm{~L}_{3}$ & $\mathrm{M}_{1}$ & $\mathrm{M}_{2}$ & $\mathrm{M}_{3}$ & $\mathrm{M}_{4}$ & $\mathrm{M}_{5}$ \\
\hline $\mathrm{Al}$ & 13 & 1.560 & - & - & - & - & - & - & - & - \\
$\mathrm{Ca}$ & 20 & 4.038 & - & - & - & - & - & - & - & - \\
$\mathrm{Ga}$ & 31 & 10.37 & 1.298 & 1.142 & 1.115 & - & - & - & - & - \\
$\mathrm{Mo}$ & 42 & 20.00 & 2.865 & 2.625 & 2.520 & - & - & - & - & - \\
$\mathrm{Ce}$ & 58 & 40.44 & 6.549 & 6.164 & 5.723 & 1.437 & 1.273 & 1.185 & - & - \\
$\mathrm{Gd}$ & 64 & 50.24 & 8.376 & 7.930 & 7.243 & 1.881 & 1.688 & 1.544 & 1.217 & 1.185 \\
\hline
\end{tabular}

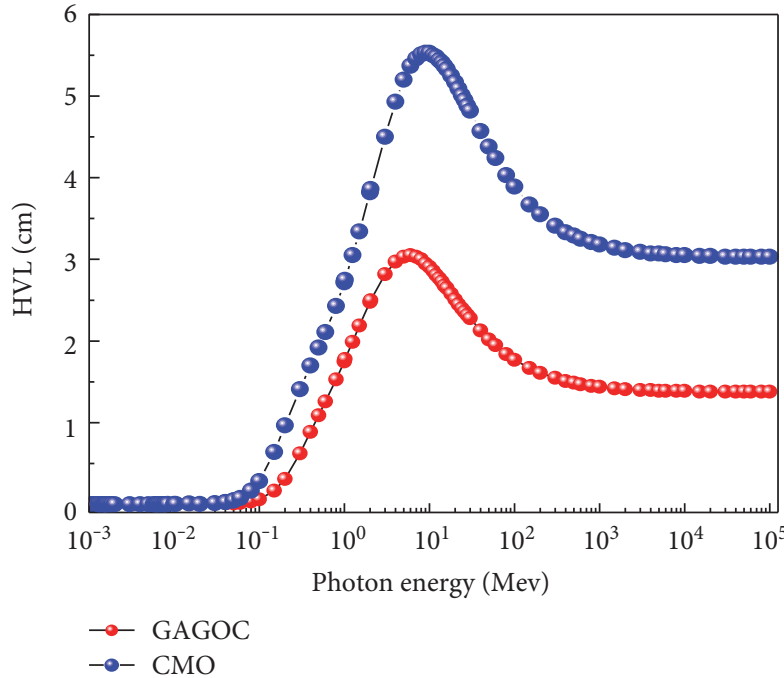

FIgURE 3: Variation of HVL versus incident photon energy for GAGOC and CMO.

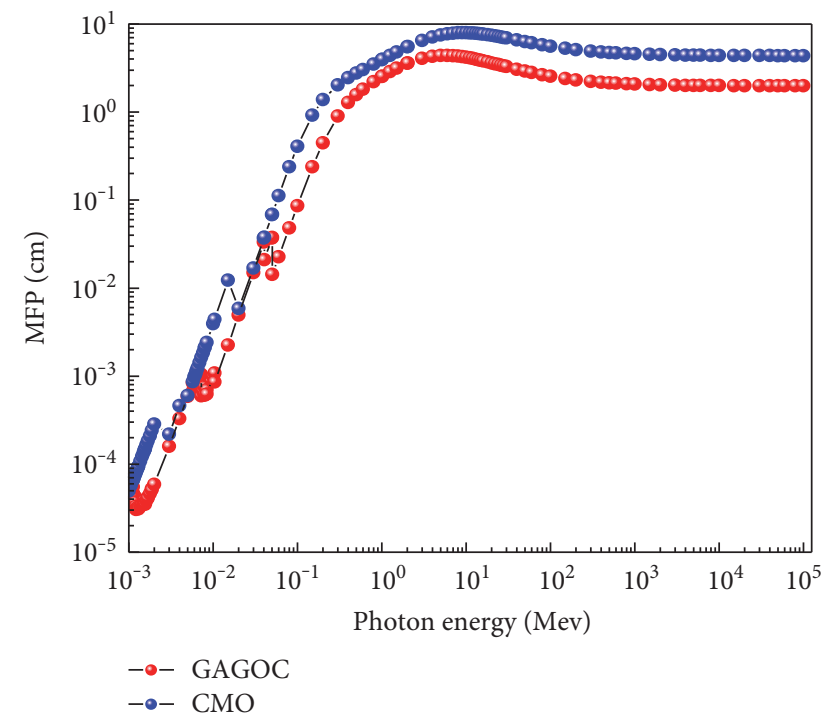

FIGURE 4: Variation of MFP versus incident photon energy for GAGOC and CMO.



FIgURE 5: Variation of effective atomic number $\left(Z_{\text {eff }}\right)$ as a function of photon energy in the range of $1 \mathrm{keV}$ to $100 \mathrm{GeV}$ for GAGOC and CMO.

TABle 2: Effective atomic numbers of the GAGOC and CMO scintillators corresponding to the $\mathrm{K}$-absorption edge energies of the constituent elements.

\begin{tabular}{lccc}
\hline \multirow{2}{*}{ Sample ID } & \multirow{2}{*}{ Element } & \multicolumn{2}{c}{ K-edge } \\
& & $Z_{\text {eff }}$ lower & $Z_{\text {eff }}$ upper \\
\hline \multirow{3}{*}{ GAGOC } & Al $(0.0505)^{\mathrm{a}}$ & 37.48 & 35.01 \\
& Ga $(0.1960)$ & 56.06 & 47.38 \\
& Ce $(0.1313)$ & 47.32 & 50.96 \\
CMO & Gd (0.4421) & 50.23 & 57.95 \\
& Ca (0.2003) & 32.48 & 27.88 \\
\hline
\end{tabular}

${ }^{\mathrm{a}}$ Refers to the elemental composition (\%).

Finally, the removal cross sections for fast neutrons $\left(\sum_{R}\right)$ for GAGOC and CMO materials can be calculated using the following equations:

$$
\begin{aligned}
& \sum_{R / \rho}=\sum_{i} w_{i}\left(\sum_{R / \rho}\right), \\
& \sum_{R}=\sum_{i} \rho_{i}\left(\sum_{R / \rho}\right),
\end{aligned}
$$




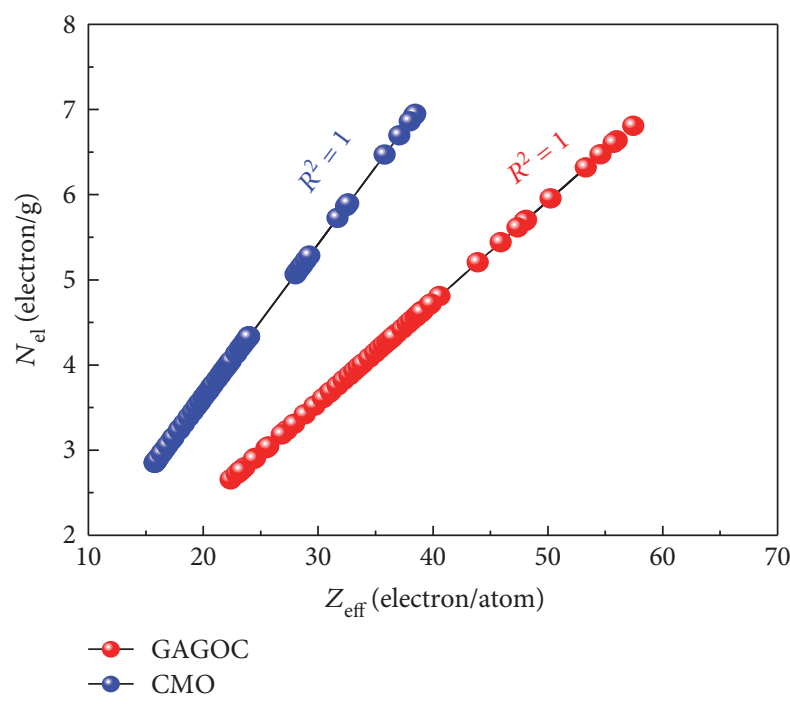

Figure 6: Correlation between effective atomic number $\left(Z_{\text {eff }}\right)$ and electron density $\left(N_{\mathrm{el}}\right)$ for GAGOC and CMO.

where $\rho_{i}$ is the partial density and $\left(\sum_{R / \rho}\right)_{i}$ is the mass removal cross section of the $i$ th element which is taken from Kaplan and Chilten $[18,19]$.

\section{Results and Discussion}

3.1. Mass Attenuation Coefficient $\left(\mu_{m}\right)$. Coherent scattering, incoherent scattering, photoelectric absorption, nuclear pair production, and electron pair production are the interaction processes of photon energy with matter. These interaction processes can explain the dependency of total mass attenuation coefficient $\left(\mu_{m}\right)$ on the photon energy, as shown in Figure 1 for GAGOC. This figure shows that the low photon energy range $(\mathrm{E}<0.3 \mathrm{MeV})$, intermediate photon energy range $(0.3<\mathrm{E}<5 \mathrm{MeV})$, and high photon energy range $(\mathrm{E}>5 \mathrm{MeV})$ are the three photon energy ranges in interaction processes. Figure 2 shows the calculated $\mu_{m}$ values of GAGOC and CMO scintillator materials. As shown in Figure 2, the $\mu_{m}$ values of the samples decrease quickly, from $3.50 \times 10^{3}$ to $1.68 \times 10^{-1} \mathrm{~cm}^{2} / \mathrm{g}$ and $4.81 \times 10^{3}$ to $1.17 \times 10^{-1} \mathrm{~cm}^{2} / \mathrm{g}$ for GAGOC and CMO, respectively, as the photon energy increases up to $0.3 \mathrm{MeV}$. In this photon energy range, the $\mathrm{K}-, \mathrm{L}_{-}$, and $\mathrm{M}$-absorption edges have been observed of $\mathrm{Al}, \mathrm{Ca}, \mathrm{Ga}, \mathrm{Mo}, \mathrm{Ce}$, and $\mathrm{Gd}$ as shown in Table 1 due to the photoelectric effect. This behavior of $\mu_{m}$ with photon energy may be attributed to the photoelectric absorption cross section which is relative to $\mathrm{E}^{3.5}$. In the photon energy range $0.3<\mathrm{E}<5 \mathrm{MeV}$, the $\mu_{m}$ values of GAGOC and CMO scintillator materials change slowly, form 0.01179 to $0.0345 \mathrm{~cm}^{2} / \mathrm{g}$ and 0.0971 to $0.0317 \mathrm{~cm}^{2} / \mathrm{g}$ for GAGOC and CMO, respectively. The difference of the $\mu_{m}$ values becomes approximately equal to zero as shown in Figure 2. This is because the process of Compton scattering is a predominant mechanism [20]. Since, the Compton scattering cross-section process is relative to $\mathrm{E}^{-1}$ and linearly changes with the $Z$ number. Figure 2 shows that, as the photon energy increases from $5 \mathrm{MeV}$ to $100 \mathrm{GeV}$, the values
TABLE 3: Theoretically and experimentally obtained values of mass attenuation coefficients and effective atomic numbers of the GAGOC and CMO scintillator materials.

(a)

\begin{tabular}{lcccc}
\hline \multirow{2}{*}{ Energy $(\mathrm{keV})$} & \multicolumn{3}{c}{ Mass attenuation coefficients $\left(\mu_{m}\right)\left(\mathrm{cm}^{2} / \mathrm{g}\right)$} \\
& GAGOC & \multicolumn{2}{c}{ CMO } \\
& This work & Exp. [1] & This work & Exp. [1] \\
\hline 287.30 & 0.179 & 0.1896 & 0.1271 & 0.1264 \\
340.80 & 0.142 & 0.1541 & 0.1116 & 0.1108 \\
399.00 & 0.118 & 0.1259 & 0.1006 & 0.1032 \\
481.60 & 0.099 & 0.1034 & 0.0900 & 0.0902 \\
562.70 & 0.087 & 0.0900 & 0.0826 & 0.0843 \\
662.00 & 0.077 & 0.0800 & 0.0758 & 0.076 \\
\hline
\end{tabular}

(b)

\begin{tabular}{lcccc}
\hline \multirow{2}{*}{ Energy $(\mathrm{keV})$} & \multicolumn{4}{c}{ Effective atomic numbers $\left(Z_{\text {eff }}\right)\left(e^{-}\right.$/atom $)$} \\
& GAGOC & \multicolumn{2}{c}{ CMO } \\
& This work & Exp. [1] & This work & Exp. [1] \\
\hline 287.30 & 32.56 & 38.6 & 17.79 & 18.12 \\
340.80 & 29.95 & 35.4 & 17.15 & 17.32 \\
399.00 & 28.07 & 31.91 & 16.74 & 17.39 \\
481.60 & 26.39 & 29.15 & 16.40 & 16.59 \\
562.70 & 25.37 & 27.56 & 16.21 & 16.66 \\
662.00 & 24.59 & 26.64 & 16.07 & 16.21 \\
\hline
\end{tabular}

of $\mu_{m}$ increase slowly, becoming constant and highly dependent on the composition of samples. This may be attributed to the fact that the pair production process is a predominant mechanism. The results show that the GAGOC scintillator material has higher $\mu_{m}$ than CMO.

3.2. HVL and MFP. The HVL and MFP results are the most suitable quantities describing the radiation attenuation. For a best radiation shielding mixture, lower HVL and MFP values are required. The values of the half-value layer as a function of photon energy are plotted in Figure 3. In the photon energy range $1-100 \mathrm{keV}$, the values of the halfvalue layer are photon energy and sample composition independent. The half-value layer values increase when the photon energy increases up to 6 and $10 \mathrm{MeV}$ for GAGOC and CMO, respectively. Above $2000 \mathrm{MeV}$, the HVL values are dependent on the composition of GAGOC and CMO. The values of HVL for GAGOC are lower than those for CMO [21].

As shown in Figure 4, the values of the mean free path (MFP) increase with increasing photon energy. In the photon energy range $1-300 \mathrm{keV}$ and $1-150 \mathrm{keV}$, the MFP values are $<1$ for GAGOC and CMO. Above $5 \mathrm{MeV}$, the values of MFP are dependent on the composition of the GAGOC and CMO samples. The values of MFP for GAGOC are lower than those for CMO. The results of HVL and MFP indicate that the GAGOC compound is the excellent $\gamma$-ray sensing a response in the broad energy range. 
TABLE 4: Equivalent atomic number $\left(Z_{\mathrm{eq}}\right)$ and G-P exposure (EBF) and energy absorption (EABF) buildup factor coefficients of GAGOC.

\begin{tabular}{|c|c|c|c|c|c|c|c|c|c|c|c|}
\hline \multirow{2}{*}{ Energy $(\mathrm{MeV})$} & \multirow{2}{*}{$Z_{\text {eq }}$} & \multicolumn{5}{|c|}{ EBF } & \multicolumn{5}{|c|}{ EABF } \\
\hline & & $b$ & $c$ & $a$ & $X_{k}$ & $d$ & $b$ & $C$ & $A$ & $X_{k}$ & $d$ \\
\hline 0.015 & 28.83 & 1.00 & 2.02 & -0.32 & 10.85 & 0.26 & 1.00 & 2.02 & -0.32 & 10.85 & 0.26 \\
\hline 0.02 & 29.00 & 1.01 & 0.10 & 0.76 & 10.78 & -1.06 & 1.01 & 0.23 & 0.44 & 12.61 & -0.51 \\
\hline 0.03 & 29.31 & 1.10 & 0.38 & 0.20 & 12.58 & -0.06 & 1.03 & 0.39 & 0.24 & 11.74 & -0.18 \\
\hline 0.04 & 29.56 & 1.19 & 0.33 & 0.23 & 14.91 & -0.09 & 1.06 & 0.39 & 0.19 & 25.33 & -0.28 \\
\hline 0.05 & 35.17 & 2.13 & 0.53 & -0.05 & 12.41 & -0.04 & 1.23 & 0.20 & 0.04 & 10.50 & 0.00 \\
\hline 0.06 & 49.54 & 2.92 & 0.22 & 0.03 & 5.66 & -0.06 & 1.56 & 0.24 & -0.03 & 20.84 & 0.04 \\
\hline 0.08 & 50.32 & 1.82 & 0.03 & 0.77 & 15.50 & -0.14 & 1.40 & 0.04 & 0.69 & 14.23 & -0.21 \\
\hline 0.1 & 50.78 & 1.40 & 0.05 & 0.68 & 13.87 & -0.30 & 1.35 & 0.07 & 0.66 & 13.51 & -0.34 \\
\hline 0.15 & 51.48 & 1.21 & 0.31 & 0.30 & 13.90 & -0.17 & 1.44 & 0.17 & 0.45 & 13.84 & -0.25 \\
\hline 0.2 & 51.89 & 1.24 & 0.49 & 0.18 & 14.50 & -0.10 & 1.59 & 0.26 & 0.35 & 13.90 & -0.20 \\
\hline 0.3 & 52.33 & 1.37 & 0.62 & 0.11 & 14.09 & -0.05 & 1.88 & 0.42 & 0.23 & 13.72 & -0.13 \\
\hline 0.4 & 52.61 & 1.49 & 0.76 & 0.07 & 14.13 & -0.05 & 2.19 & 0.55 & 0.17 & 13.87 & -0.12 \\
\hline 0.5 & 52.77 & 1.56 & 0.84 & 0.05 & 14.08 & -0.04 & 2.26 & 0.67 & 0.12 & 13.87 & -0.09 \\
\hline 0.6 & 52.89 & 1.60 & 0.90 & 0.03 & 13.93 & -0.03 & 2.31 & 0.74 & 0.09 & 13.72 & -0.08 \\
\hline 0.8 & 53.01 & 1.64 & 0.97 & 0.01 & 13.90 & -0.02 & 2.29 & 0.83 & 0.06 & 13.62 & -0.06 \\
\hline 1 & 53.06 & 1.65 & 1.00 & 0.01 & 13.34 & -0.02 & 2.22 & 0.88 & 0.05 & 13.51 & -0.05 \\
\hline 1.5 & 52.13 & 1.56 & 1.11 & -0.02 & 14.09 & -0.01 & 1.95 & 1.00 & 0.01 & 13.62 & -0.03 \\
\hline 2 & 49.55 & 1.56 & 1.11 & -0.02 & 13.08 & -0.01 & 1.85 & 1.00 & 0.02 & 13.12 & -0.04 \\
\hline 3 & 45.55 & 1.54 & 1.06 & 0.00 & 12.91 & -0.03 & 1.72 & 0.94 & 0.04 & 13.24 & -0.06 \\
\hline 4 & 42.05 & 1.50 & 1.02 & 0.02 & 13.36 & -0.04 & 1.60 & 0.91 & 0.05 & 13.52 & -0.07 \\
\hline 5 & 42.79 & 1.52 & 0.94 & 0.05 & 13.60 & -0.07 & 1.57 & 0.83 & 0.08 & 13.79 & -0.10 \\
\hline 6 & 42.27 & 1.50 & 0.92 & 0.06 & 13.82 & -0.08 & 1.51 & 0.81 & 0.10 & 14.00 & -0.11 \\
\hline 8 & 41.62 & 1.53 & 0.88 & 0.08 & 14.13 & -0.10 & 1.48 & 0.80 & 0.11 & 14.28 & -0.12 \\
\hline 10 & 41.26 & 1.49 & 0.96 & 0.06 & 14.20 & -0.08 & 1.40 & 0.88 & 0.08 & 14.35 & -0.10 \\
\hline 15 & 41.00 & 1.55 & 1.11 & 0.04 & 14.18 & -0.06 & 1.39 & 1.01 & 0.06 & 14.31 & -0.08 \\
\hline
\end{tabular}

TABLE 5: Equivalent atomic number $\left(Z_{\mathrm{eq}}\right)$ and G-P exposure (EBF) and energy absorption (EABF) buildup factor coefficients of CMO.

\begin{tabular}{|c|c|c|c|c|c|c|c|c|c|c|c|}
\hline \multirow{2}{*}{ Energy $(\mathrm{MeV})$} & \multirow{2}{*}{$Z_{\mathrm{eq}}$} & \multicolumn{5}{|c|}{ EBF } & \multicolumn{5}{|c|}{ EABF } \\
\hline & & $b$ & $c$ & $a$ & $X_{k}$ & $d$ & $b$ & $c$ & $A$ & $X_{k}$ & $d$ \\
\hline 0.015 & 17.98 & 1.01 & 0.49 & 0.14 & 29.23 & -0.28 & 1.01 & 0.49 & 0.14 & 29.24 & -0.28 \\
\hline 0.02 & 29.95 & 1.14 & 0.27 & 0.24 & 11.00 & -0.97 & 1.03 & 0.39 & 0.41 & 13.09 & -0.47 \\
\hline 0.03 & 31.09 & 1.51 & 0.50 & 0.19 & 15.78 & -0.08 & 1.11 & 0.51 & 0.22 & 14.41 & -0.17 \\
\hline 0.04 & 31.62 & 1.72 & 0.33 & 0.20 & 16.53 & -0.08 & 1.14 & 0.38 & 0.18 & 24.93 & -0.23 \\
\hline 0.05 & 31.96 & 1.61 & 0.27 & 0.10 & 12.65 & -0.09 & 1.15 & 0.27 & 0.14 & 11.68 & -0.07 \\
\hline 0.06 & 32.21 & 1.48 & 0.26 & 0.23 & 14.67 & -0.14 & 1.18 & 0.25 & 0.41 & 14.64 & -0.16 \\
\hline 0.08 & 32.54 & 1.34 & 0.32 & 0.37 & 14.10 & -0.15 & 1.26 & 0.30 & 0.33 & 14.28 & -0.16 \\
\hline 0.1 & 32.78 & 1.24 & 0.44 & 0.21 & 13.84 & -0.11 & 1.32 & 0.44 & 0.20 & 17.56 & -0.11 \\
\hline 0.15 & 33.12 & 1.42 & 0.61 & 0.13 & 14.14 & -0.07 & 1.88 & 0.42 & 0.24 & 13.72 & -0.15 \\
\hline 0.2 & 33.34 & 1.61 & 0.71 & 0.10 & 13.87 & -0.06 & 2.48 & 0.53 & 0.19 & 13.67 & -0.13 \\
\hline 0.3 & 33.59 & 1.76 & 0.91 & 0.03 & 13.30 & -0.03 & 2.71 & 0.78 & 0.09 & 13.30 & -0.07 \\
\hline 0.4 & 33.69 & 1.83 & 1.04 & 0.00 & 12.56 & -0.02 & 2.75 & 0.93 & 0.04 & 12.89 & -0.05 \\
\hline 0.5 & 33.75 & 1.85 & 1.10 & -0.01 & 11.73 & -0.02 & 2.65 & 1.02 & 0.02 & 12.52 & -0.04 \\
\hline 0.6 & 33.80 & 1.85 & 1.14 & -0.02 & 10.77 & -0.01 & 2.55 & 1.07 & 0.00 & 11.99 & -0.03 \\
\hline 0.8 & 33.82 & 1.83 & 1.16 & -0.02 & 9.93 & -0.01 & 2.37 & 1.11 & -0.01 & 10.81 & -0.02 \\
\hline 1 & 33.89 & 1.80 & 1.16 & -0.03 & 9.98 & -0.01 & 2.23 & 1.12 & -0.01 & 9.83 & -0.02 \\
\hline 1.5 & 32.14 & 1.70 & 1.18 & -0.04 & 15.25 & 0.01 & 1.95 & 1.13 & -0.02 & 9.65 & -0.01 \\
\hline 2 & 29.13 & 1.69 & 1.12 & -0.02 & 8.94 & 0.00 & 1.84 & 1.11 & -0.02 & 9.53 & -0.01 \\
\hline 3 & 26.83 & 1.63 & 1.06 & 0.00 & 11.84 & -0.01 & 1.68 & 1.03 & 0.00 & 12.51 & -0.02 \\
\hline 4 & 26.26 & 1.55 & 1.03 & 0.01 & 12.93 & -0.02 & 1.56 & 1.00 & 0.01 & 13.96 & -0.03 \\
\hline 5 & 25.91 & 1.48 & 1.01 & 0.01 & 13.12 & -0.03 & 1.48 & 0.97 & 0.02 & 14.14 & -0.04 \\
\hline 6 & 25.71 & 1.44 & 0.98 & 0.02 & 13.38 & -0.04 & 1.40 & 0.98 & 0.02 & 14.33 & -0.04 \\
\hline 8 & 25.45 & 1.35 & 0.98 & 0.03 & 13.68 & -0.04 & 1.30 & 0.96 & 0.03 & 13.99 & -0.04 \\
\hline 10 & 25.38 & 1.30 & 0.95 & 0.04 & 13.98 & -0.06 & 1.24 & 0.96 & 0.04 & 14.26 & -0.05 \\
\hline 15 & 25.39 & 1.20 & 0.95 & 0.05 & 14.35 & -0.06 & 1.15 & 0.96 & 0.04 & 14.59 & -0.05 \\
\hline
\end{tabular}





FIgURE 7: EBF and EABF variation for GAGOC and CMO with incident photon energy at 1, 10, 20, 30, and $40 \mathrm{mfp}$.

3.3. Effective Atomic Numbers $\left(Z_{\text {eff }}\right)$ and Electron Densities $\left(N_{\mathrm{el}}\right)$. Figure 5 shows $Z_{\mathrm{eff}}$ as a function of photon energy for GAGCO and CMO scintillator materials. In the photon energy range $1 \mathrm{keV}-100 \mathrm{GeV}$, the values of $Z_{\text {eff }}$ are dependent on the composition of GAGCO and CMO scintillator materials. As shown in Figure 5, there are two peaks at 10 and $60 \mathrm{keV}$ for GAGCO due to the K-absorption edges of Ga and Gd, respectively. The other two peaks for CMO at 4 and $20 \mathrm{keV}$ are due to the $\mathrm{K}$-absorption edges of $\mathrm{Ca}$ and $\mathrm{Mo}$, respectively. In the photon energy range $0.03-1 \mathrm{MeV}$, the values of $Z_{\text {eff }}$ decrease rapidly as the photon energy increases and then increase slowly up to $200 \mathrm{MeV}$. As the photon energy increases up to $100 \mathrm{GeV}$, the values of $Z_{\text {eff }}$ become nearly constant for both scintillator materials. It is worth noting that different values of $Z_{\text {eff }}$ occur due to their corresponding $\mathrm{K}$-absorption edges. We have calculated the $Z_{\text {eff }}$ values at K-edge energies of the constituent elements of the scintillators and obtained two possible $Z_{\text {eff }}$ values, one corresponding to the lower side and the other to the upper side of the same energy (Table 2) [22].

The $N_{\mathrm{el}}$ results of the investigated GAGCO and CMO scintillator materials in the photon energy $1 \mathrm{keV}-100 \mathrm{GeV}$ have been computed according to (6). There are slight variations in $N_{\mathrm{el}}$ results for various GAGCO and CMO scintillator materials where a higher result of $N_{\mathrm{el}}$ would indicate an increased probability of photon-electron energy transfer and energy deposition into the material. The results of $N_{\mathrm{el}}$ present identical photon energy dependence to what was observed for $Z_{\text {eff }}$ [23]. This behavior has been confirmed in Figure 6 which showing a correlation of $Z_{\mathrm{eff}}$ and $N_{\mathrm{el}}$.

Besides, the calculated $\mu_{m}$ and $Z_{\mathrm{eff}}$ values of GAGOC and $\mathrm{CMO}$ scintillators were compared with the experimental values at different energies for the two scintillator materials taken from [1] and the results were shown in Table 3. In general, it can be seen that the experimental $\mu_{m}$ and $Z_{\text {eff }}$ values show good agreement with the theoretical values.

3.4. Exposure Buildup Factors (EBF) and Gamma Ray Energy Absorption (EABF). Equivalent atomic number $\left(Z_{\mathrm{eq}}\right)$ and $\mathrm{G}$ $\mathrm{P}$ exposure $(\mathrm{EBF})$ and energy absorption $(\mathrm{EABF})$ buildup factor coefficients of GAGOC and CMO are listed in Tables 4 and 5. The variation of EBF and EABF values with photon energy at 1, 10, 20,30, and $40 \mathrm{mfp}$ of GAGCO and CMO scintillator materials has been presented in Figure 7 . 

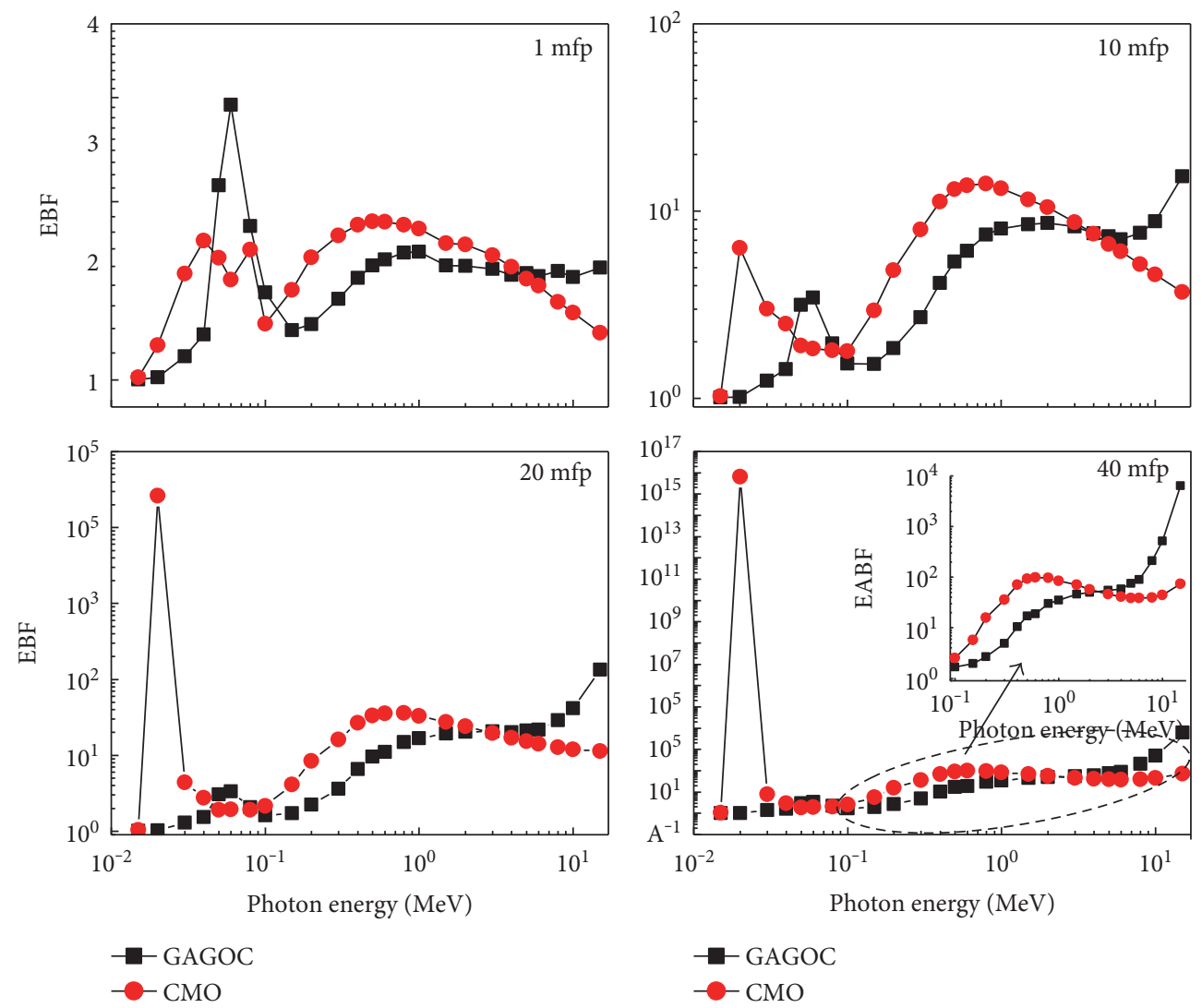

FIgure 8: EBF variation for GAGOC and CMO with incident photon energy at 1, 10, 20, and $40 \mathrm{mfp}$.

This figure shows that the maximum values of EBF and EABF are dependent on the composition of scintillator materials and penetration depth and shifted to higher energy. Also, it is clear that the EBF and EABF values increase up to the maximum value with increase in photon energy and then decrease with further increase in photon energy. In the low-photon energy region, the EBF and EABF values are smallest because a great number of photons were absorbed because the predominant interaction process is the photoelectric effect. In the intermediate photon energy region, the $\mathrm{EBF}$ and $\mathrm{EABF}$ values are highest because the predominant interaction process is the Compton scattering. In the high-energy region, the photons have been absorbed again because the predominant interaction process is the pair production. The EBF and EABF results of GAGCO and $\mathrm{CMO}$ observe sharp peaks at 20 and $60 \mathrm{keV}$ which may be attributed to K-absorption edges of Mo and Gd, respectively. Due to the occurrence of multiple scatterings at high penetration depths, the highest values of EBF and EABF were observed at a penetration depth of $40 \mathrm{mfp}$ while the lowest values were observed at $1 \mathrm{mfp}$. Figures 8 and 9 show the variation of buildup factors (EBF and EABF) with incident photon energy for GAGCO and $\mathrm{CMO}$ at different penetration depths $(1,10,20$, and $40 \mathrm{mfp})$. It is clear that at the selected penetration depths, the GAGCO in general has the lowest EBF and EABF values which emphasize that the GAGCO compound is superior as a gamma ray sensor material.
3.5. Fast Neutron Removal Cross Section $\left(\sum_{R}\right)$. The removal cross section for fast neutron of GAGCO and CMO scintillator materials is listed in Table 6. The values of $\sum_{R}$ are 0.121 and $0.048 \mathrm{~cm}^{-1}$ for GAGCO and CMO, respectively. The height value of $\sum_{R}$ was found for GAGCO-this may be attributed to the fact that the elements that have a high $Z$ number are greatly accountable to the removal of fast neutrons as the elements that have a low $Z$ number do [23].

\section{Conclusions}

The gamma ray mass attenuation coefficient, half-value layer, mean free path, effective atomic number, and effective electron densities have been calculated using the WinXCom program in the energy range $1 \mathrm{keV}-100 \mathrm{GeV}$ of GAGCO and CMO scintillator materials. The EBF and $\mathrm{EABF}$ values in the energy range $0.015-15 \mathrm{MeV}$ and penetration depth of up to $40 \mathrm{mfp}$ have been computed using the G-P fitting parameter method for GAGCO and $\mathrm{CMO}$ scintillator materials. In addition, the values of removal cross section for fast neutrons have been calculated. The calculated values present that the GAGCO showed excellent $\gamma$-rays and neutrons sensing a response in the broad energy range due to higher values for mass attenuation coefficient and effective atomic number and lower values for the half-value layer, mean free path, and buildup factors. 

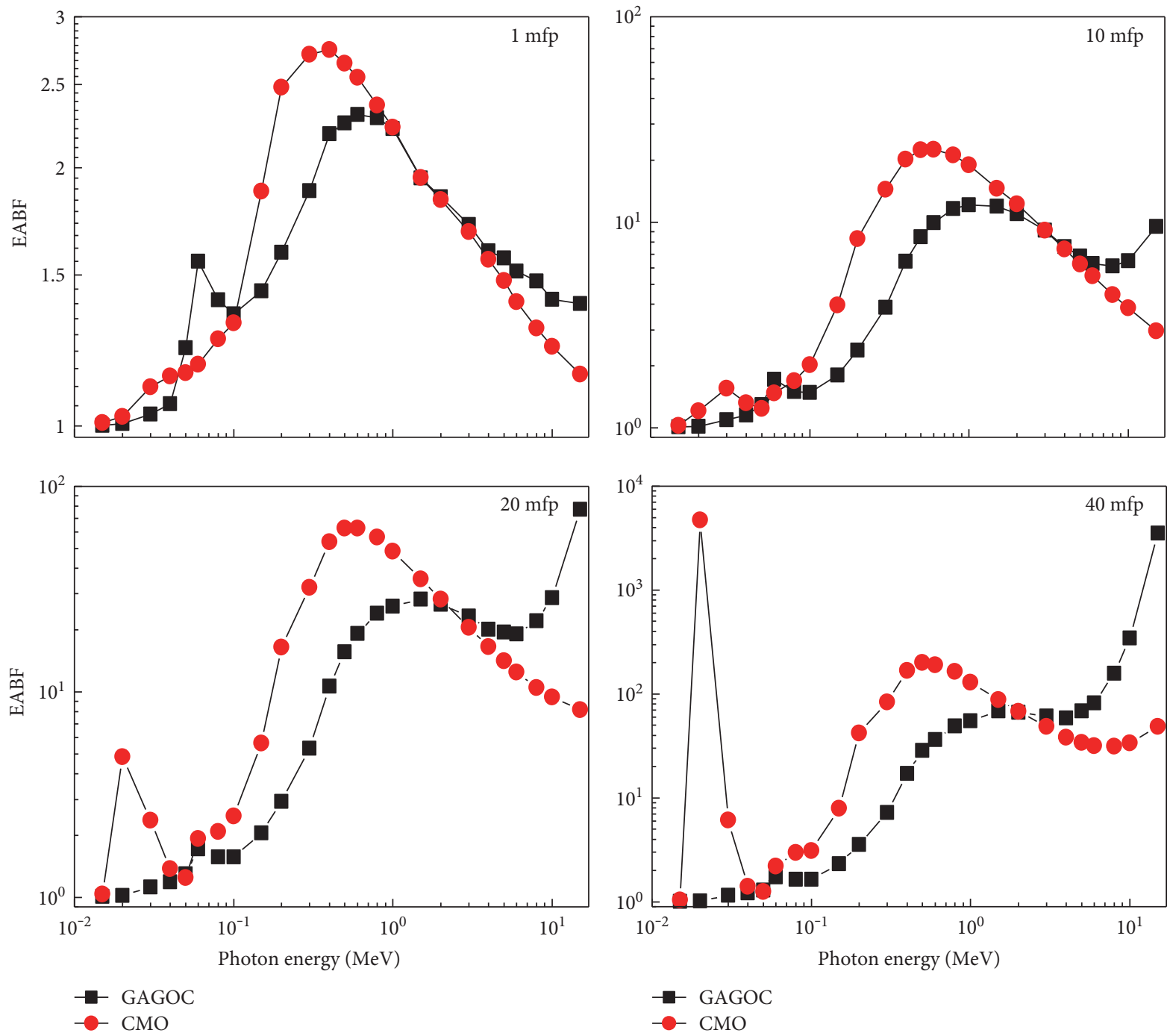

Figure 9: EABF variation for GAGOC and CMO with incident photon energy ant 1, 10, 20, and $40 \mathrm{mfp}$.

TABLE 6: Calculation values of the fast neutron effective removal cross-sections for GAGOC and CMO.

\begin{tabular}{lcccc}
\hline Elements & $W_{i}$ & $\begin{array}{c}\sum_{(R / \rho)} \\
\left(\mathrm{cm}^{2} / \mathrm{g}\right)\end{array}$ & $\rho\left(\mathrm{g} / \mathrm{cm}^{3}\right)$ & $\sum_{R}\left(\mathrm{~cm}^{-1}\right)$ \\
\hline GAGOC $\left(6.63 \mathrm{~g} / \mathrm{cm}^{3}\right)$ & & & & \\
$\mathrm{O}$ & 0.179939 & 0.0405 & 0.001429 & 0.007288 \\
$\mathrm{Al}$ & 0.050575 & 0.0293 & 2.698000 & 0.001482 \\
$\mathrm{Ga}$ & 0.196037 & 0.013 & 5.907000 & 0.002548 \\
$\mathrm{Ce}$ & 0.131318 & 0.0126 & 6.770000 & 0.001655 \\
$\mathrm{Gd}$ & 0.442132 & 0.0119 & 7.895000 & 0.005261 \\
Total & & & & $\mathbf{0 . 1 2 1}$ \\
$\mathrm{CMO}\left(4.2 \mathrm{~g} / \mathrm{cm}^{3}\right)$ & & & & \\
$\mathrm{O}$ & 0.179939 & 0.0405 & 0.001429 & 0.007288 \\
$\mathrm{Ca}$ & 0.050575 & 0.0243 & 1.540000 & 0.001229 \\
$\mathrm{Mo}$ & 0.196037 & 0.0151 & 10.22000 & 0.002960 \\
Total & & & & $\mathbf{0 . 0 4 8}$ \\
\hline
\end{tabular}

\section{Conflicts of Interest}

The authors declare that they have no conflicts of interest.

\section{Acknowledgments}

The authors gratefully acknowledge the financial support for this study which is from the Malaysian Ministry of Higher Education (MOHE) through the Fundamental Research Grant Scheme, and also, the financial support from the University of Tabuk and Al-Azhar University is gratefully acknowledged.

\section{References}

[1] W. Chaiphaksa, P. Limkitjaroenporn, H. J. Kim, and J. Kaewkhao, "The mass attenuation coefficients, effective atomic numbers and effective electron densities for GAGG:Ce and $\mathrm{CaMoO}_{4}$ scintillators," Progress in Nuclear Energy, vol. 92, pp. $48-53,2016$. 
[2] S. Gupta and G. S. Sidhu, "Gamma-rays absorption studies of garnet series of gemstones at $1 \mathrm{keV}$ to $100 \mathrm{GeV}$ : theoretical calculation," IOSR Journal of Engineering, vol. 4, pp. 01-08, 2014.

[3] S. G. Gounhalli, A. Shantappa, and S. M. Hanagodimath, "Studies on effective atomic numbers and electron densities of some chemical explosives in the energy range $1 \mathrm{KeV}-100$ GeV," Journal of Chemical and Pharmaceutical Research, vol. 4, pp. 2545-2563, 2012.

[4] H. Hideo, K. Fumito, G. Shinji et al., "Measurements of photon mass attenuation coefficients for Ge and BGO crystals at $10 \mathrm{Me}$ V," Journal of Nuclear Science and Technology, vol. 45, pp. 1228-1232, 2008.

[5] B. O. El-bashir, M. I. Sayyed, M. H. M. Zaid, and K. A. Matori, "Comprehensive study on physical, elastic and shielding properties of ternary $\mathrm{BaO}-\mathrm{Bi}_{2} \mathrm{O}_{3}-\mathrm{P}_{2} \mathrm{O}_{5}$ glasses as a potent radiation shielding material," Journal of Non-Crystalline Solids, vol. 468, pp. 92-99, 2017.

[6] Y. Yoshiki, K. Masashi, K. Masaru et al., "Measurement of effective atomic numbers using energy-resolved computed tomography," Journal of Nuclear Science and Technology, vol. 51, pp. 1256-1263, 2014.

[7] M. H. M. Zaid, K. A. Matori, H. J. Quah et al., "Investigation on structural and optical properties of SLS-ZnO glasses prepared using a conventional melt quenching technique," Journal of Materials Science: Materials in Electronics, vol. 26, pp. 3722-3729, 2015.

[8] I. Shams and A. Mostafa, "Effect of $\mathrm{Bi}_{2} \mathrm{O}_{3}$ in borate-telluritesilicate glass system for development of gamma-rays shielding materials," Journal of Alloys and Compounds, vol. 695, pp. 302-310, 2017.

[9] I. Shams, "Effective atomic number and mass attenuation coefficient of $\mathrm{PbO}-\mathrm{BaO}-\mathrm{B}_{2} \mathrm{O}_{3}$ glass system," Radiation Physics and Chemistry, vol. 120, pp. 33-37, 2016.

[10] M. I. Sayyed and H. Elhouichet, "Variation of energy absorption and exposure buildup factors with incident photon energy and penetration depth for boro-tellurite $\left(\mathrm{B}_{2} \mathrm{O}_{3}-\mathrm{TeO}_{2}\right)$ glasses," Radiation Physics and Chemistry, vol. 130, pp. 335-342, 2017.

[11] K. A. Matori, M. I. Sayyed, H. A. A. Sidek, M. H. M. Zaid, and V. P. Singh, "Comprehensive study on physical, elastic and shielding properties of lead zinc phosphate glasses," Journal of Non-Crystalline Solids, vol. 457, pp. 97-103, 2017.

[12] G. J. Hine, "Effective atomic numbers of materials for various gamma ray interactions," Physics Review, vol. 85, pp. 725737, 1952.

[13] J. Y. Yeom, S. Yamamoto, S. E. Derenzo et al., "First performance results of Ce: GAGG scintillation crystals with silicon photomultipliers," IEEE Transactions on Nuclear Science, vol. 60, pp. 988-992, 2013.

[14] S. David, M. Georgiou, E. Fysikopoulos, and G. Loudos, "Evaluation of a SiPM array coupled to a $\mathrm{Gd}_{3} \mathrm{Al}_{2} \mathrm{Ga}_{3} \mathrm{O}_{12}$ : $\mathrm{Ce}$ (GAGG: Ce) discrete scintillator," Physica Medica, vol. 31, pp. 763-766, 2015.

[15] A. M. A. Mostafa, S. A. M. Issa, and M. I. Sayyed, "Gamma ray shielding properties of $\mathrm{PbO}-\mathrm{B}_{2} \mathrm{O}_{3}-\mathrm{P}_{2} \mathrm{O}_{5}$ doped with WO3," Journal of Alloys and Compounds, vol. 708, pp. 294-300, 2017.

[16] M. I. Sayyed, "Half value layer, mean free path and exposure buildup factor for tellurite glasses with different oxide compositions," Journal of Alloys and Compounds, vol. 695, pp. 31913197, 2017.
[17] ANSI/ANS-6.4.3, Gamma Ray Attenuation Coefficient and Buildup Factors for Engineering Materials, American Nuclear Society, La Grange Park, IL, USA, 1991.

[18] M. F. Kaplan, Concrete Radiation Shielding, Longman scientific and Technology, Lonman Group UK, Limited, Essex, England, 1989.

[19] A. B. Chilten, J. K. Shultis, and R. E. Faw, Principle of Radiation Shielding, Prentice-Hall, Englewood Cliffs, NJ, USA, 1984.

[20] M. I. Sayyed, "Bismuth modified shielding properties of zinc boro-tellurite glasses," Journal of Alloys and Compounds, vol. 688, pp. 111-117, 2016.

[21] S. A. M. Issa, T. A. Hamdalla, and A. A. A. Darwish, "Effect of $\mathrm{ErCl}_{3}$ in gamma and neutron parameters for different concentration of $\mathrm{ErCl}_{3}-\mathrm{SiO}_{2}$ (EDFA) for the signal protection from nuclear radiation," Journal of Alloys and Compounds, vol. 698, pp. 234-240, 2017.

[22] M. Kurudirek, M. Büyükyıldız, and Y. Özdemir, "Effective atomic number study of various alloys for total photon interaction in the energy region of $1 \mathrm{keV}-100 \mathrm{GeV}$," Nuclear Instruments and Methods in Physics Research A, vol. 613, pp. 251-256, 2010.

[23] V. P. Singh, N. M. Badiger, N. Chanthima, and J. Kaewkhao, "Evaluation of gamma-ray exposure buildup factors and neutron shielding for bismuth borosilicate glasses," Radiation Physics and Chemistry, vol. 98, pp. 14-21, 2014. 

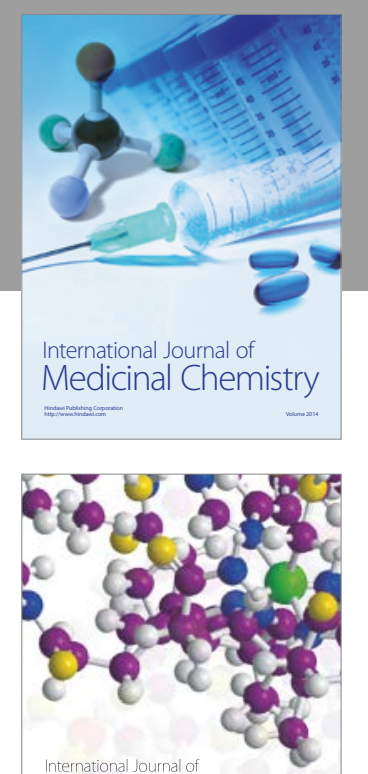

Carbohydrate Chemistry

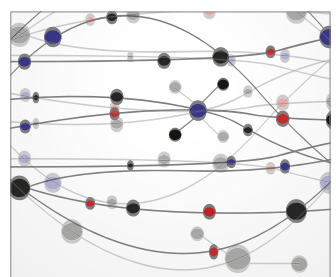

The Scientific World Journal
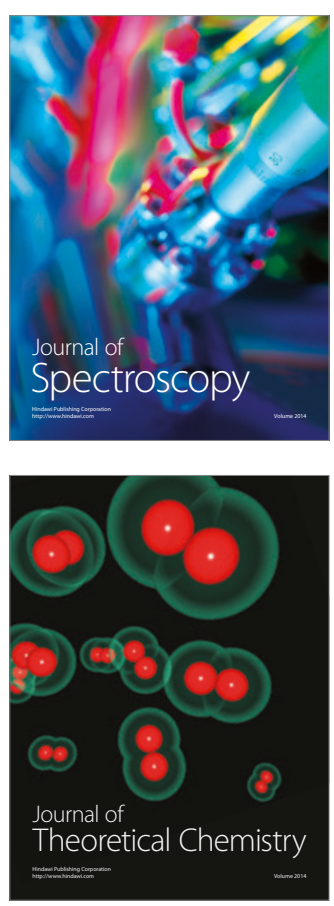
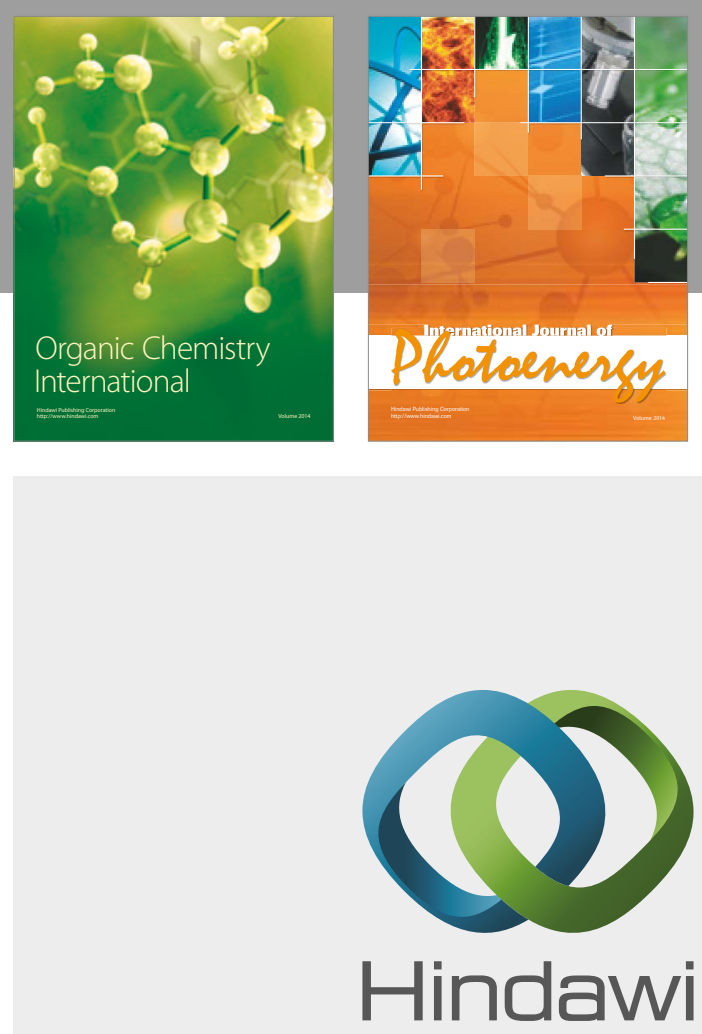

Submit your manuscripts at

https://www.hindawi.com

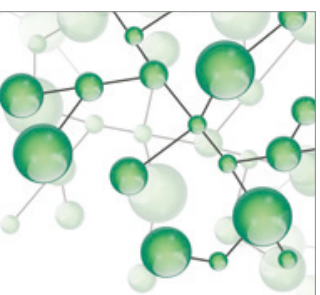

International Journal of

Inorganic Chemistry

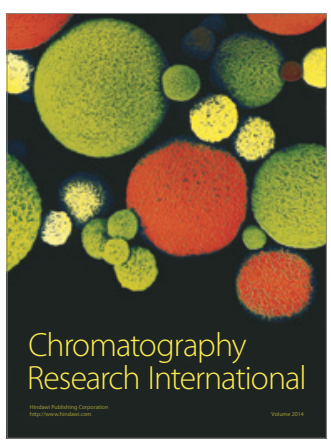



Applied Chemistry
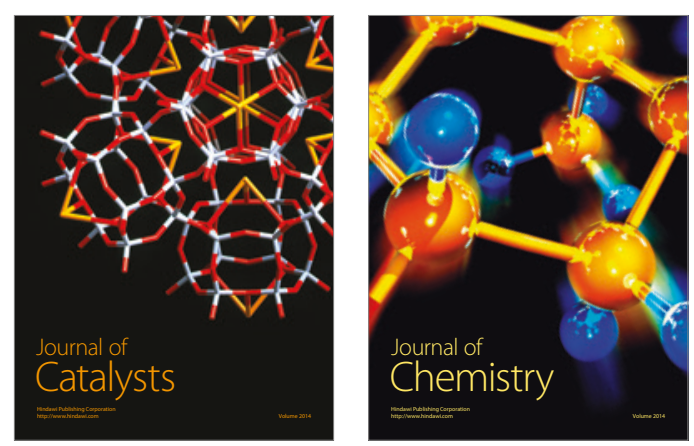
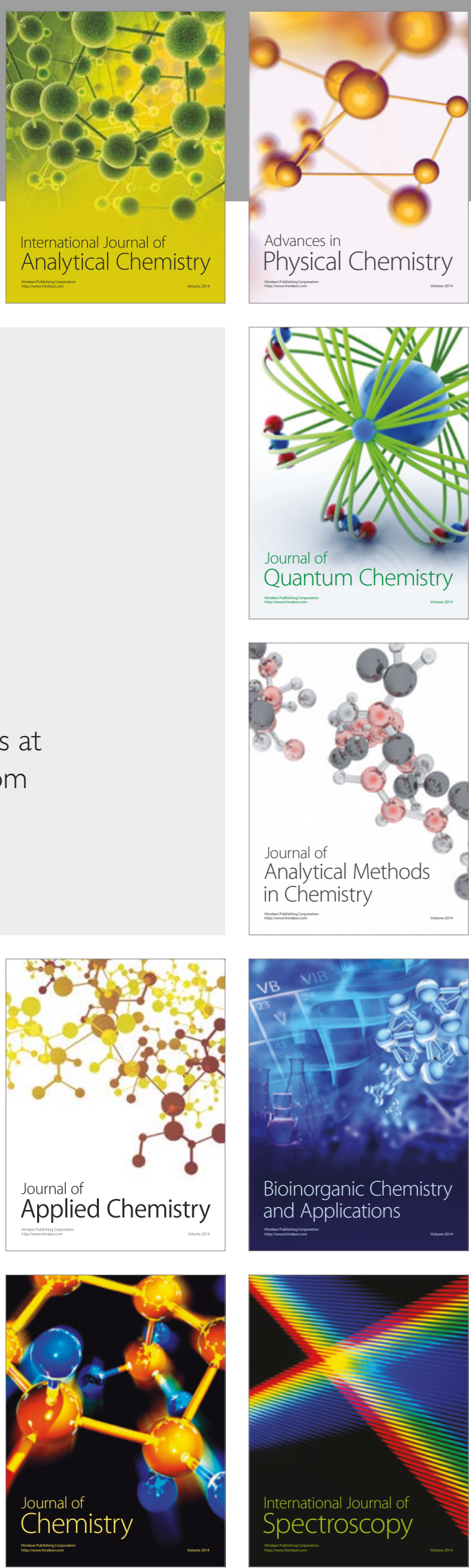